\title{
Dividing attention impairs metacognitive control more than monitoring
}

\author{
Yaoping Peng ${ }^{1}$. Jonathan G. Tullis ${ }^{2}$
}

Accepted: 7 May 2021 / Published online: 15 June 2021

(C) The Psychonomic Society, Inc. 2021

\begin{abstract}
Students consistently report multitasking (e.g., checking social media, texting, watching Netflix) when studying on their own (e.g., Junco \& Cotton, Computers \& Education, 59[2], 505-514, 2012). Multitasking impairs explicit learning (e.g., Carrier, Rosen, Cheever, \& Lim, Developmental Review, 35, 64-78, 2015), but the impact of multitasking on metacognitive monitoring and control is less clear. Metacognition may compete with ongoing cognitive processing for mental resources (e.g., Nelson \& Narens, The Psychology of Learning and Motivation, 26, 125-141, 1990) and would be impaired by dividing attention; alternatively, metacognition may require little attention (e.g., Boekaerts \& Niemivirta, Handbook of Self-Regulation [pp. 417-450], 2000) and would not be impacted by dividing attention. Across three experiments, we assessed the influence of divided attention on metacognition. Participants made item-by-item judgements of learning (JOLs) after studying word pairs under full or divided attention (Experiment 1) and made restudy choices (Experiments $2 \& 3$ ). Dividing attention had little impact on the resolution of learners' metacognitive monitoring, but significantly impaired calibration of monitoring, the relationship between monitoring and control, and the efficacy of metacognitive control. The data suggest that monitoring may require few cognitive resources, but controlling one's learning (e.g., planning what to restudy and implementing a plan) may demand significant mental resources.
\end{abstract}

Keywords Metacognition $\cdot$ Divided attention $\cdot$ Metacognitive control $\cdot$ Metacognitive monitoring

Students multitask frequently while studying, even though dividing attention between tasks impairs learning. Learners send text messages while in class, listen to music while doing homework, and scroll through social media while taking notes. For example, $51 \%$ of college students report sending text messages during most of their studying (Junco \& Cotton, 2012). Dividing attention between tasks reliably impairs explicit memory. For example, sending text messages during class leads to worse memory for class-related content and lower GPAs (e.g., Burak, 2012; Ellis et al., 2010) and multitasking during study outside of class impairs exam scores (Patterson, 2017). Prior research has shown clear and consistent impairments of divided attention on explicit learning; we

Yaoping Peng

sabrina6217@gmail.com

1 Research Institute of Educational Science, Hunan University, Changsha 410082, Hunan Province, China

2 Department of Educational Psychology, University of Arizona, Tucson, AC, USA extend existing research by examining the impact of divided attention on learners' metacognitive monitoring and control.

How students control their learning determines how much they learn, and students typically make effective decisions during study that enhance their learning. For example, learners make appropriate study decisions about how to allocate study time across items (Tullis \& Benjamin, 2011), what items to restudy (Kornell \& Metcalfe, 2006; Tullis \& Benjamin, 2012), how to schedule study presentations in time (Benjamin \& Bird, 2006; Son, 2004), and even when to choose retrieval practice over rereading (Tullis et al., 2018). Learners make effective study choices because their choices are driven by accurate, personal monitoring of their own processing (Nelson \& Leonesio, 1988; Tullis \& Fraundorf, 2017). Accurate monitoring leads to effective control, which ultimately results in better learning (e.g., Mazzoni \& Cornoldi, 1993; Thiede, 1999; Thiede et al., 2003). Extant research has examined the efficacy of metacognition largely under full attention; here, we examined the efficacy of metacognition under divided attention.

Competing theories suggest differential impacts of divided attention on metacognition. Multiple models of self-regulation 
suggest that dividing attention may disrupt metacognition because metacognition requires attentional resources. Kanfer and Ackerman (1989), for example, posit that learners allocate limited attentional resources between on-task, off-task, and self-regulated (i.e., metacognitive) behaviors. Similarly, Nelson and Narens' (1990) model of metacognition proposes two levels of cognitive activities that must compete for attentional resources: object-level processes (i.e., processing stimuli) and meta-level processes (i.e., metacognitive monitoring and control). Further, the COPES model of metacognition presumes that attentional resources are required to complete operations on information and evaluate the products of those operations in relation to standards (Winne \& Hadwin, 1998). In these views, metacognitive monitoring and control are effortful and compete with the primary tasks for attentional resources. If task demands are high and cognitive resources are demanded by the object level, learners might be unable to effectively monitor and control their learning at the meta level.

Alternate theories suggest that most metacognitive processes may require few attentional resources. Monitoring, for example, may be largely automatic when it is driven by processing fluency. Learners heuristically link more fluent processing with better learning, and therefore, they may easily assign higher judgements of learning (JOLs) to more fluent processes (e.g., Miele \& Molden, 2010; but see Peng \& Tullis, 2019). Further, metacognition is often driven by habits, which require few attentional resources (Ariel et al., 2011; Ariel \& Dunlosky, 2013).

Learners often recognize that dividing attention impairs explicit learning (e.g., Barnes \& Dougherty, 2007), but struggle to accurately predict the decrement. For example, students who send text messages frequently during classes report that their grades suffer, but students cannot accurately estimate how much dividing attention impairs learning (Junco \& Cotton, 2011). In fact, participants sometimes overestimate the impact of divided attention on performance (Finley et al., 2014). Yet, prior studies almost exclusively assess monitoring under divided attention by comparing aggregate predictions of performance across divided and full attention conditions (but see Hanczakowski et al., 2018). In contrast, we examine the impact of divided attention on itemby-item JOLs. Aggregate JOLs, which are solicited before or after learning, primarily rely on learners' general beliefs about divided attention, while item-by-item JOLs made during learning may rely on learners' subjective experience of learning (and rely less on general beliefs or task conditions; Koriat, 1997). Processing fluency may influence learners' item-by-item JOLs through non-resource-demanding heuristics (Miele \& Molden, 2010; Undorf \& Erdfelder, 2015); consequently, dividing attention may impair recall but have minimal impact on the accuracy of item-by-item monitoring judgements.

Eliciting item-by-item JOLs allows us to test the impact of divided attention on both the calibration and resolution of those judgments. Calibration indicates whether learners are over- or under-confident, while metacognitive resolution indicates whether judgments accurately reflect which particular items are eventually recalled and which are not. Prior research on the impact of divided attention has focused on calibration of monitoring judgments (e.g., Finley et al., 2014; Hanczakowski et al., 2018), but the impact of divided attention on resolution has not been assessed. Calibration and resolution are driven by different mental processes, such that dividing attention may impact calibration more than resolution (Connor et al., 1997; Nelson, 1984). Further, accurate resolution of JOLs is vital because it determines how learners allocate resources (e.g., attention, study time, restudy opportunities) between to-belearned items (Metcalfe \& Finn, 2008).

If metacognition requires cognitive resources, dividing attention between tasks will impair metacognitive resolution and control. In this case, multitasking may be especially problematic during student-controlled learning. Alternatively, if metacognitive processes require few attentional resources, divided attention may not interfere with monitoring and control and learners may be able to compensate for impaired learning through effective metacognition.

\section{Experiment 1}

Experiment 1 tested the accuracy of metacognitive monitoring under divided attention. While previous research examined aggregate JOLs (which are based upon general beliefs about dividing attention; e.g., Undorf \& Erdfelder, 2015), we examined learners' item-by-item JOLs, which allowed us to compare the resolution and calibration of judgments across divided and full attention conditions.

\section{Method}

Participants We first conducted a pilot study where divided and full attention conditions were manipulated within participants with 34 participants. A significant order effect was found, which suggested the order of attention conditions differentially impacted memory (results are reported in the Supplemental Materials).

We conducted a power analysis based on the effect size of the difference in JOLs between the divided attention group and the full attention group in the pilot study (Cohen's $d$ of 0.60 ). The results of the power analysis showed that in order to obtain an effect size of 0.60 , with a power of 0.8 , an $\alpha$ of 0.05 in an independent-samples $t$ test, 45 participants in each group were needed in Experiment 1. Ninety participants were recruited from the University of Arizona; 80 of them completed this experiment for partial course credit, and 10 completed the experiment for monetary compensation.

Materials Seventy-two related word pairs were selected from University of South Florida Free Association Norms (Nelson 
et al., 1998). The cue-to-target associative strength of word pairs ranged between 0.03 to 0.05 . Thirty-six unrelated word pairs were created by randomly separating pairs and recombining the target and cue words for each participant. Half of the word pairs (18 related and 18 unrelated) were randomly assigned to the first block, and the other half were assigned to the second block.

Procedure All participants first learned a continuous reaction task (CRT; Craik et al., 2000). Participants heard three different tones with frequencies of $200 \mathrm{~Hz}, 700 \mathrm{~Hz}$, and $1600 \mathrm{~Hz}$ through headphones. When a participant heard a particular tone, they were asked to press a corresponding key as quickly as possible. The $1 \mathrm{key}$ was paired with the low tone, the $2 \mathrm{key}$ with the middle tone, and the 3 key with the high tone. Participants learned the CRT task by matching a tone with its paired key one at a time. Then, during a CRT training block, 10 tones were presented one at a time with a duration of $250 \mathrm{~ms}$ and an interstimulus interval of $1,000 \mathrm{~ms}$. Participants had to correctly classify eight of the 10 tones in order to move to the next stage. If they did not meet this training criterion, they retrained on the key tone pairings and completed an additional test block until they reached training criterion. Participants then completed four more practice blocks, each of which included 10 more random practice tones.

After completing four CRT practice blocks, participants studied 36 word pairs for a later memory test. Participants were alternatively assigned to the full attention (FA) condition or the divided attention (DA) condition. The instructions informed participants that they would need to recall the target when given the cue during the test. Participants were instructed to make a JOL after studying each word pair. Participants were given six ratings of JOLs to choose among (from $0=$ definitely will not remember, 20, 40, 60, 80, to $100=$ definitely will remember), which were presented as clickable boxes at the bottom of the screen. Participants were instructed to click on the box with the appropriate JOL and to make JOLs as quickly as possible. Participants were instructed that the word-learning and CRT tasks were equally important. Participants responded to the CRT with their left hand and the keyboard; they completed the JOL task with their right hand and the mouse.

During the study block, word pairs were presented one at a time in a random order for 2 seconds each. Then, the JOL prompt appeared, asking participants to predict how well they would remember the target word when given the cue. After participants clicked on one of the JOL boxes, the next word was presented. After the study block, participants took the cued recall memory test. Cues were presented in a new random order. In the FA condition, participants studied and recalled the words without performing the CRT. In the DA condition, participants studied the words while also performing the CRT in which the tones were presented, with an interstimulus interval of $3 \mathrm{~s}$. All participants completed the cued recall test without interference from the CRT task. After completing a first cycle of study and test, participants completed an additional study/test cycle in the opposite attention condition. We included the second block only to fully replicate the pilot, and the results of the second block are included in the Supplemental Materials.

\section{Results}

CRT test performance Participants correctly identified $76 \%$ of tones during the divided attention task $(S D=18 \%)$.

Cued recall As shown in Fig. 1, participants remembered significantly more word pairs under full attention than divided attention, $t(89)=4.41, p<.001$, Cohen's $d=0.90$.

Accuracy of JOLs We present JOLs as the proportion of word pairs participants predicted to remember (by dividing JOLs by 100). Resolution of JOLs was calculated as the intraindividual gamma correlation between JOLs and cued recall. Resolution of JOLs did not differ between participants under divided attention $(M=0.51, S D=0.30)$ and full attention $(M=0.53$, $S D=0.26), t(89)=0.45, p=.65$, Cohen's $d=0.17$. Similarly, the gamma correlation between learners' JOLs and the relatedness of word pairs were not significantly different between participants under divided attention $(M=0.63, S D=0.38)$ and those under full attention $(M=0.72, S D=0.32), t(89)=1.25$, $p=.21$, Cohen's $d=0.26$.

As shown in Fig. 1, participants under divided attention predicted they would remember significantly fewer word pairs than participants under full attention, $t(89)=2.82, p=.01$, Cohen's $d=0.59$. Calibration of JOLs was calculated by subtracting participants' proportion cued recall from their

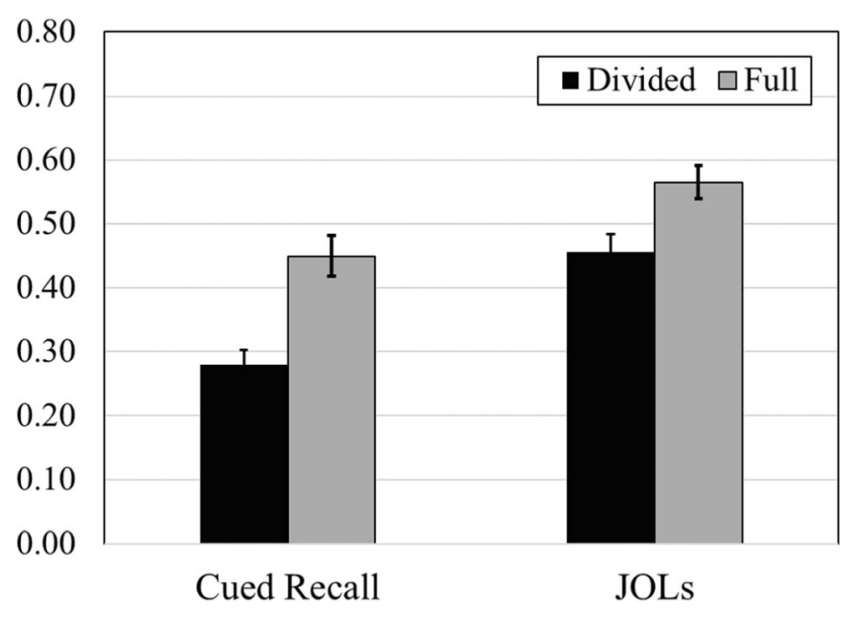

Fig. 1 Participants' cued recall and JOLs in Experiment 1. Error bars represent one standard error of the mean above and below the sample mean 
average JOL. While both groups overestimated their memory, no significant difference was found in the calibration of JOLs between participants in the divided attention $(M=0.18, S D=$ $0.23)$ group and those in the full attention group $(M=0.11, S D$ $=0.26), t(89)=1.20, p=.23$, Cohen's $d=0.29$.

\section{Discussion}

Dividing attention significantly impaired participants' memory, but had little impact on learners' metacognitive monitoring. Specifically, dividing attention did not affect the strength of the relationship between learners' JOLs and (1) word pair relatedness or (2) later cued recall. Dividing attention may have little impact on metacognitive monitoring of word pairs because processing fluency may primarily drive metacognitive predictions about recall of word pairs. Assessing and interpreting processing fluency may require few attentional resources (Efklides, 2011). We return to these conclusions after replicating and extending the results in Experiments 2 and 3.

\section{Experiment 2}

While Experiment 1 showed that dividing attention minimally disrupted learners' metacognitive monitoring, we examined whether dividing attention adversely impacted learners' metacognitive control in Experiment 2. Effective metacognitive control may require more attentional resources than monitoring because learners' plans must consider multiple variables, including task difficulty, rate of learning, and total study time (e.g., Ariel et al., 2009; Son \& Sethi, 2006). Consequently, attentional resources may quickly become overwhelmed as learners track ongoing tasks, remember monitoring judgments, and formulate and execute a study plan (Thiede \& Dunlosky, 1999).

In this experiment, the efficacy of learners' restudy choices was tested through the honor/dishonor paradigm (Kornell \& Metcalfe, 2006). Learners were asked to choose half of the word pairs to restudy. Half of learners' restudy choices were honored, so that learners restudied what they chose; the other half of learners' restudy choices were dishonored, such that learners restudied the word pairs they did not chose and dropped those they chose to restudy. If learners' restudy choices are effective, honoring learners' choices will yield better memory performance than dishonoring learners' choices. If dividing attention affects the efficacy of metacognitive control, the impact of honoring learners' choices will depend upon control condition.

\section{Methods}

Participants and materials As in Experiment 1,90 participants from the University of Arizona were recruited. Eighty word pairs from the University of South Florida Free Association Norms (Nelson et al., 1998) were used. Forty word pairs were randomly assigned to the first block, among which half were related word pairs, and the other half were unrelated word pairs.

Procedures The experiment proceeded like Experiment 1, but included two significant changes. First, during study, participants chose half of the word pairs to restudy. Immediately after making their JOL, participants chose whether to restudy the word pair or not. The word pairs continued to be displayed on the screen while participants made their restudy choice. Participants clicked either a "Restudy" box or a "Done" box, which were presented near the center of the screen with the restudy box above the done box. Participants were instructed that they could only choose to restudy 20 word pairs; participants had to drop the other 20 word pairs from additional study. The number of word pairs chosen to restudy and to drop from study were shown at the right of the selection boxes (e.g., "13/20 pairs have been chosen to be restudied"). When a participant selected 20 word pairs to be done or to restudy, that option was removed from the screen and participants had to select the only remaining option for the remaining word pairs. Participants in the divided attention group made JOLs and restudy choices while performing the secondary task.

Second, after completing the study and choice phase, participants restudied word pairs. Half of the word pairs chosen to be restudied were dropped from the restudy list and half of the word pairs chosen to be dropped were added to the restudy list. During restudy, each word pair was presented for $4 \mathrm{sec}-$ onds in a random order. All participants restudied the word pairs under full attention. After restudying 20 word pairs, participants took a cued recall test for all 40 word pairs in an entirely random order.

\section{Results}

CRT Participants under divided attention correctly identified $59 \%(S D=18 \%)$ of tones during study.

JOLs No significant difference was found between participants' average JOLs under full attention $(M=0.58, S D=$ $0.12)$ and under divided attention $(M=0.56, S D=0.14)$, $t(89)=0.70, p=.49$, Cohen's $d=0.15$. The gamma correlation between JOLs and the relatedness of word pairs did not differ between divided $(M=0.72, S D=0.29)$ and full attention condition $(M=0.76, S D=0.24), t(89)=0.88, p=.38$, Cohen's $d=0.15$.

We calculated the resolution and calibration of participants' JOLs for word pairs that were not restudied. No significant difference was found in the gamma correlations between JOLs and cued recall (i.e., resolution) between participants under divided $(M=0.50, S D=0.39)$ or full attention $(M=$ 
0.53, $S D=0.39), t(93)=0.38, p=0.70$, Cohen's $d=0.08$. However, participants under divided attention overestimated their memory $(M=0.29, S D=0.23)$ more than participants under full attention $(M=0.14, S D=0.25), t(93)=2.96, p=$ .004 , Cohen's $d=0.62$.

Restudy choices To determine how JOLs affected restudy choices, we calculated the gamma correlation between participants' JOLs and their restudy choices. Under both conditions, the gamma correlations between JOLs and restudy choices were negative, indicating that participants chose to restudy poorly learned items. The gamma correlation was significantly lower for participants under full attention $(M=-0.64, S D=$ $0.50)$ than participants under divided attention $(M=-0.45, S D$ $=0.41), t(89)=1.98, p=.05$, Cohen's $d=0.42$, indicating that the relationship between JOLs and restudy choices was stronger under full attention than divided attention. A violin plot depicting the density of gamma correlation between JOLs and restudy choices across groups is displayed in Fig. 2. The violin plot suggests more noise in participants' restudy choices under divided attention than under full attention.

Cued recall A 2 (honored/dishonored) $\times 2$ (divided/full attention) mixed design analysis of variance (ANOVA) conducted on participants' cued recall revealed a significant interaction between attention and honor conditions, $F(1,88)=6.25, p=.01, \eta_{\mathrm{p}}{ }^{2}=.07$ (see Fig. 3). ${ }^{1}$ Participants under divided attention remembered fewer word pairs than those under full attention, $F(1,88)=10.25$, $p=.002, \eta_{\mathrm{p}}^{2}=.10$. The main effect of honoring choices did not reach significance, $F(1,88)=2.69, p=.10, \eta_{\mathrm{p}}^{2}=.03$. Planned paired $t$ tests showed that, under full attention, honoring participants' restudy choices yielded greater cued recall than dishonoring their choices, $t(89)=2.94, p=.004$, Cohen's $d=$ 0.29 . Under divided attention, however, participants' cued recall did not significantly differ between honored and dishonored restudy choices, $t(89)=0.59, p=.56$, Cohen's $d=0.05$.

\section{Discussion}

Experiment 2 showed that dividing attention had little impact on metacognitive monitoring, but significantly impaired metacognitive control. Honoring participants' restudy choices only benefited memory for participants under full attention. We seek to replicate these results with new materials in Experiment 3.

\footnotetext{
${ }^{1}$ We repeated the $2 \times 2$ ANOVA on the subset of word pairs for which participants still had both options available (i.e., free trials). As in the full analysis, a significant interaction between attention and honor conditions was revealed, $F(1,88)=11.05, p=.001, \eta_{\mathrm{p}}{ }^{2}=0.112$. Participants from the divided attention group remembered fewer word pairs than participants from the full attention group, $F(1,88)=10.55, p=.002, \eta_{\mathrm{p}}{ }^{2}=.11$. The main effect of the honor condition did not reach significance, $F(1,88)=2.74, p=.10, \eta_{\mathrm{p}}{ }^{2}$ $=0.03$.
}

\section{Experiment 3}

In Experiments 1 and 2, the relatedness of word pairs was a strong metacognitive cue about item difficulty. In Experiment 3 , we tested learners' metacognitive monitoring and control under divided attention when no strong cues indicating item difficulty were available.

\section{Methods}

Participants We recruited participants on Amazon Mechanical Turk until we received complete data from at least 45 participants in each condition. Ultimately, we received complete data from 94 participants. Participants were paid $\$ 4$ to complete the experiment.

Materials Forty weakly related word pairs from the University of South Florida Free Association Norms (Nelson et al., 1998) were collected, with a range of cue-target associative strengths from 0.049 to 0.051 .

Procedures The procedures were the same with Experiment 2 except for four changes. First, all studied word pairs were weakly-related; participants never studied unassociated pairs. This eliminated a strong, salient cue about item difficulty. Second, participants only completed one study-test block to minimize the compensation needed to pay for participant time. Third, the interstimulus interval between tones were increased to $4 \mathrm{~s}$ to bolster performance on the secondary task. Finally, participants completed the experiment online with their own devices and in their own locations due to COVID-19.

\section{Results}

CRT Participants under divided attention correctly identified $72 \%(S D=14 \%)$ of the tones during study.

JOLs For the items that were not restudied, participants under divided attention predicted they would remember significantly fewer word pairs $(M=0.57, S D=0.17)$ than participants under full attention $(M=0.66, S D=0.14), t(93)=2.95, p=$ .004 , Cohen's $d=0.64$. Despite reduced mnemonic predictions, calibration of JOLs for nonrestudied items under divided attention $(M=0.19, S D=0.27)$ was significantly worse than under full attention $(M=0.08, S D=0.26), t(93)=1.99, p$ $=.0498$, Cohen's $d=0.42$. For word pairs that were not restudied, no significant difference was found in the gamma correlation between JOLs and cued recall (i.e., resolution) between participants under divided attention $(M=0.13, S D$ $=0.48)$ and those under full attention $(M=0.24, S D=0.43)$, $t(93)=1.14, p=.26$, Cohen's $d=0.24$. 


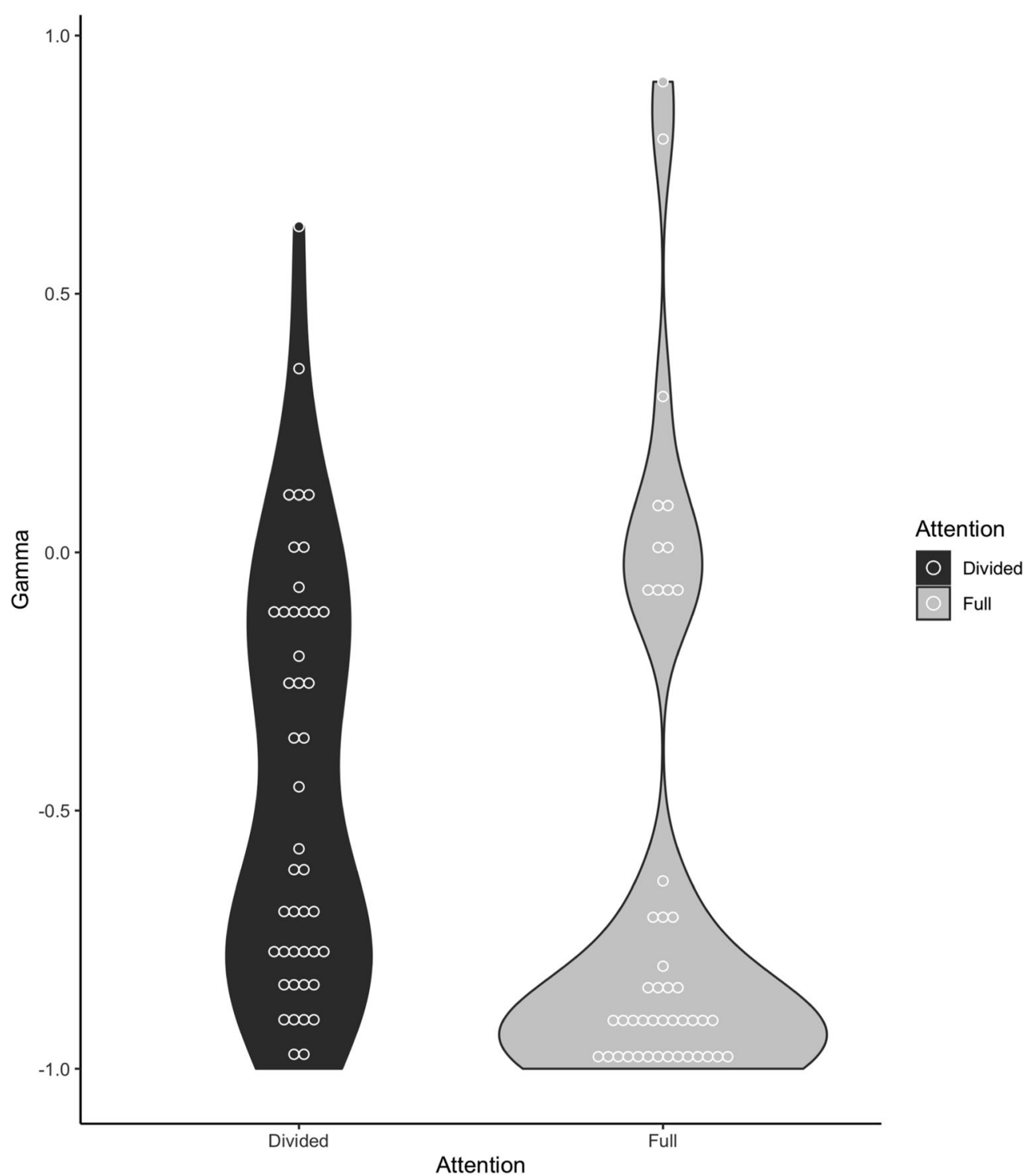

Fig. 2 Violin plots of the within-participant gamma correlations between JOLs and restudy choices in Experiment 2

Restudy choices As in Experiment 2, we computed the gamma correlation between participants' restudy choices and JOLs. The gamma correlations were negative in both groups, indicating that participants chose poorly learned word pairs to restudy; further, the gamma correlation was significantly lower under full attention $(M=-0.69, S D=0.37)$ than under divided attention $(M=-0.48, S D=0.39), t(93)=2.65, p=$ .009 , Cohen's $d=0.55$, indicating a stronger relationship between learners' restudy choices and their JOLs under full attention. As shown in Fig. 4, there was greater noise in participants' restudy choices under divided attention than under full attention.

Cued recall A 2 (honored/dishonored) $\times 2$ (attention) ANOVA conducted on participants' cued recall revealed a main effect of honoring choices, $F(1,92)=6.79, p=.01, \eta_{\mathrm{p}}{ }^{2}=.07$ and $\mathrm{a}$ main effect of attention, $F(1,92)=8.15, p=.005, \eta_{\mathrm{p}}{ }^{2}=.08$ (see Fig. 5). ${ }^{2}$ The interaction did not reach significance, $F(1$, $92)=0.79, p=.38, \eta_{\mathrm{p}}{ }^{2}=.01$. Planned paired $t$ tests showed that, under full attention, honoring participants' restudy choices yielded greater cued recall than dishonoring their choices, $t(45)=2.48, p=.02$, Cohen's $d=0.37$. Under divided attention, however, participants' cued recall did not significantly differ between honored and dishonored restudy choices, $t(47)=1.21, p=.23$, Cohen's $d=0.18$.

\footnotetext{
${ }^{2}$ We also conducted the $2 \times 2$ ANOVA for items where participants still had both choices available. When considering only the nonforced trials, a significant interaction between honoring and attention condition was found, $F(1,92)$ $=8.46, p=.005, \eta_{\mathrm{p}}{ }^{2}=.084$. Further, both the main effect of honor condition, $F(1,92)=9.07, p=.003, \eta_{\mathrm{p}}^{2}=.09$, and the main effect of attention, $F(1,92)=$ $7.93, p=.006, \eta_{\mathrm{p}}{ }^{2}=.08$, reached significance.
} 


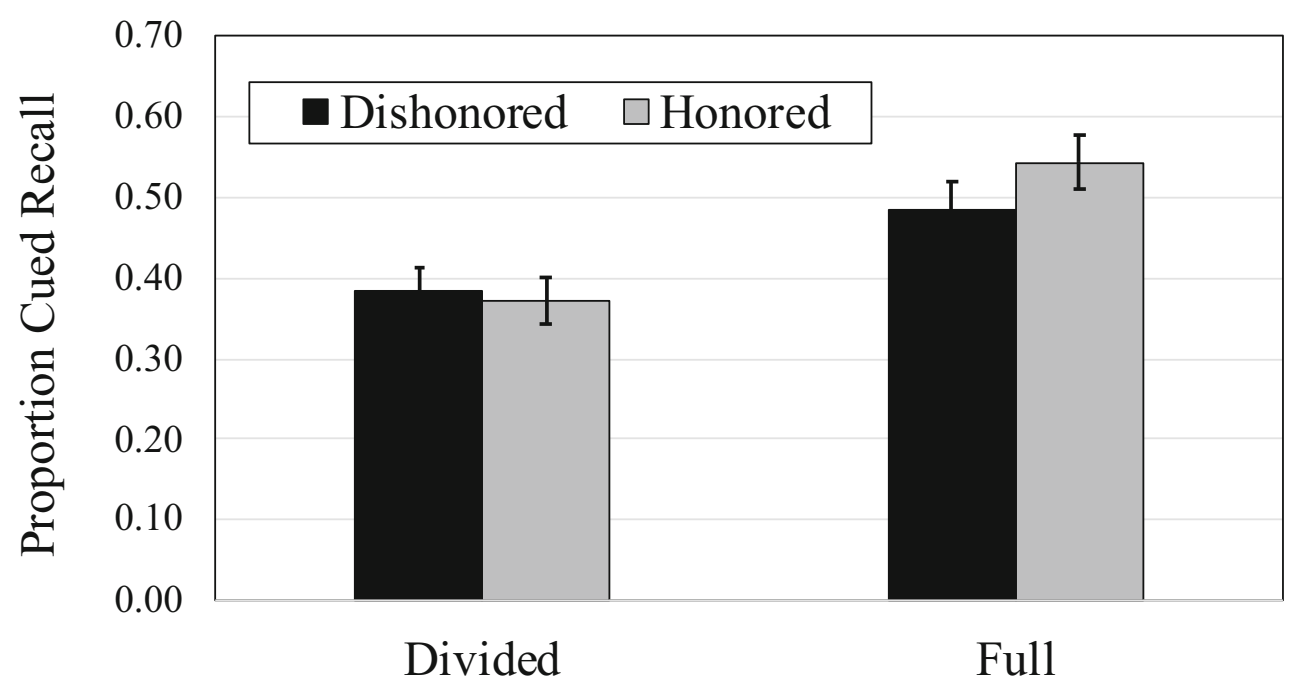

Fig. 3 Cued recall as a function of attention and honor conditions in Experiment 2. Error bars represent one standard error of the mean above and below the sample mean

\section{Discussion}

Experiment 3 largely replicated the results from Experiment 2: Dividing attention had little impact on the resolution of learners' metacognitive predictions, but significantly impaired calibration, the relationship between monitoring and control, and the efficacy of metacognitive control. Eliminating the strong cue about word pair relatedness significantly impaired learners' resolution compared with Experiments 1 and 2. Yet, even without strong cues about the memorability of word pairs, dividing attention did not significantly impair the correlation between mnemonic judgments and recall.

As in Experiment 2, study choices were not as strongly tied to JOLs under divided attention as under full attention. Consequently, only participants under full attention significantly benefited from honoring their choices. Planning and executing an appropriate mnemonic strategy likely consumed cognitive resources that competed with the divided attention task and ultimately reduced the efficacy of metacognitive control over learning.

\section{General discussion}

Dividing attention between tasks minimally impaired the resolution of metacognitive monitoring but significantly impaired calibration of monitoring and the efficacy of metacognitive control across three experiments. Learners accurately differentiated between well-learned and poorly learned stimuli under both full and divided attention. However, under divided attention, learners overestimated their cued recall more than learners under full attention. Finally, learners under divided attention were unable to use their monitoring to guide their control as effectively as learners under full attention. Restudy choices made under divided attention were consequently less effective than those under full attention.

Dividing attention did not significantly impair the resolution of learners' JOLs across the three experiments. More specifically, the attention condition did not affect the relationship between JOLs and recall. Even when relatedness could not cue item difficulty, minimal differences existed between the resolution of full and divided attention groups. In this study, resolution of learners' JOLs for word pairs may largely rely upon processing fluency, which may not require many attentional resources to notice and translate into JOLs (Efklides, 2011). The lack of impact of divided attention on metacognitive resolution mirrors the lack of effect of divided attention on implicit memory (e.g., Mulligan, 1998, 2008); interestingly, both of these processes may rely upon processing fluency and have little requirement for attention.

Dividing attention did not impact the resolution of JOLs in our three experiments, but may impact the accuracy of other monitoring judgments that rely on different categories of metacognitive cues. For example, dividing attention can impair the accuracy of Feeling of Knowing judgments (FOKs; Sacher et al., 2013). Accurate FOKs may depend on learners' abilities to retrieve partial memories about each item, which may be constrained by attentional resources (e.g., Hertzog et al., 2010; Sacher et al., 2009). Further, dividing attention may limit the impact of explicit metacognitive cues on monitoring judgments more than implicit metacognitive cues. Learners may need to allocate more attentional resources to account for explicit beliefs than implicit fluencies (e.g., Undorf et al., 2018).

While dividing attention did not significantly affect learners' metacognitive resolution, dividing attention significantly impaired learners' control over restudy. Under divided 


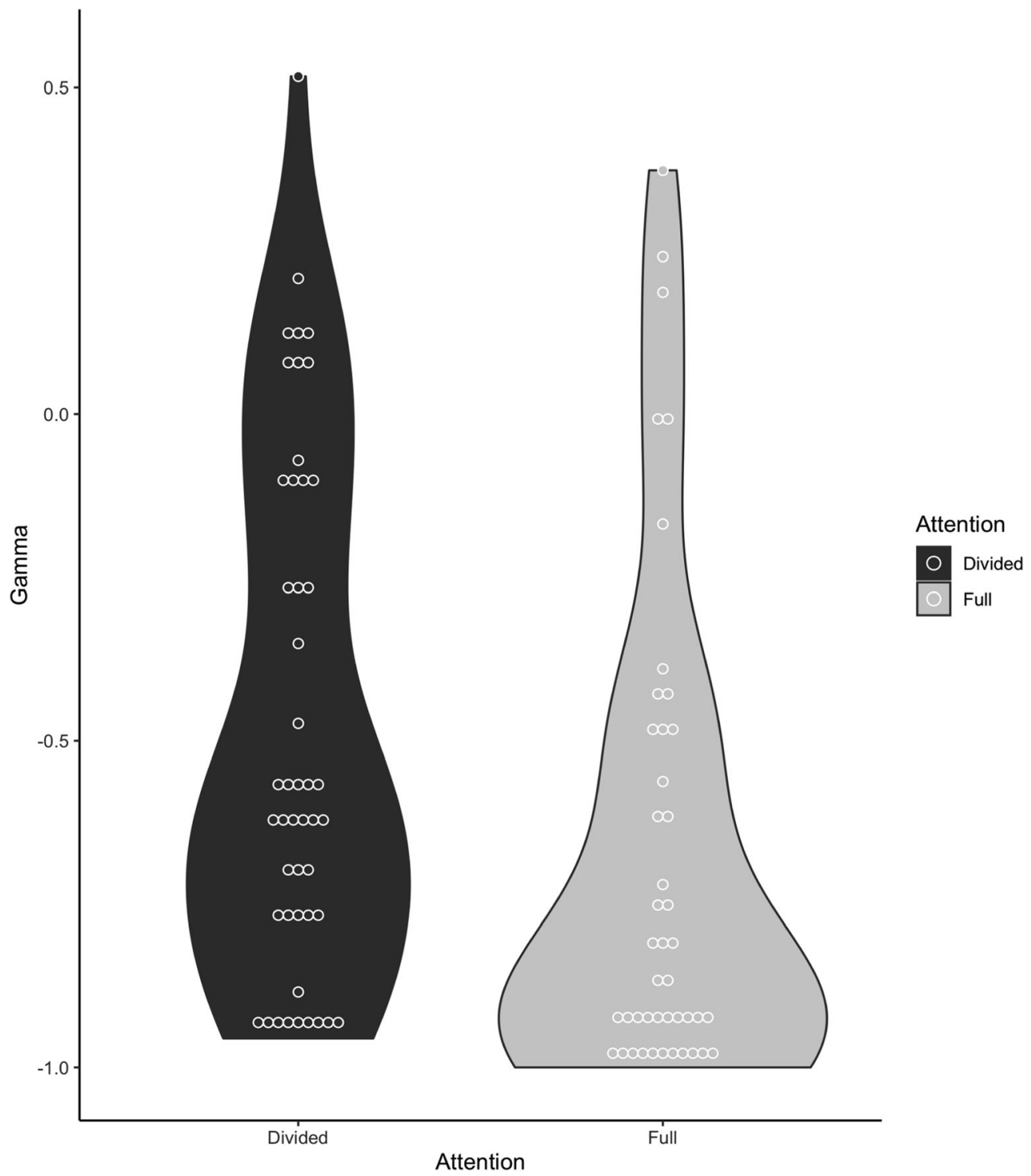

Fig. 4 Violin plots of the within-participant gamma correlations between JOLs and restudy choices in Experiment 3

attention, learners struggled to apply monitoring to control (e.g., Beaman et al., 2014), as indicated by the weaker relationship between monitoring judgments and control under divided attention. With limited attentional resources, learners are unable to utilize their monitoring to generate an effective plan or to transfer their plans into effective restudy choices (e.g., Ariel, 2013; Ariel et al., 2009; Dunlosky \& Thiede, 2004). Dividing attention, consequently, negated the benefits of learner-controlled study. A central implication of these results is that successfully controlling one's own learning requires attention and diverting attention from metacognitive control can impair one's self-regulated learning. The requirement of attention for effective self-regulated control is consistent with the agenda-based model of metacognition (Ariel, 2013; Ariel et al., 2009). In the agenda-based model, learners' metacognitive control requires top-down attentional processes to construct agendas based upon task structures and to enact those agendas through study choices.

The attentional burden of planning and executing restudy strategies may depend upon the affordances of the format of study choices and on students' individual differences (Thiede \& Dunlosky, 1999). Under sequential choices, as used in Experiments 2 and 3, learners are forced to hold a broad restudy strategy, the number of study items remaining, and the state of learning for each item in mind (Thiede \& Dunlosky, 1999). In contrast, when study choices are presented in a simultaneous array, working memory demands are reduced (Thiede \& Dunlosky, 1999). Similarly, individual differences in working memory may impact how dividing attention impacts metacognitive control (Dunlosky \& Thiede, 2004). Learners with higher working memory spans may be able to adeptly control their learning, even when attention is divided. 


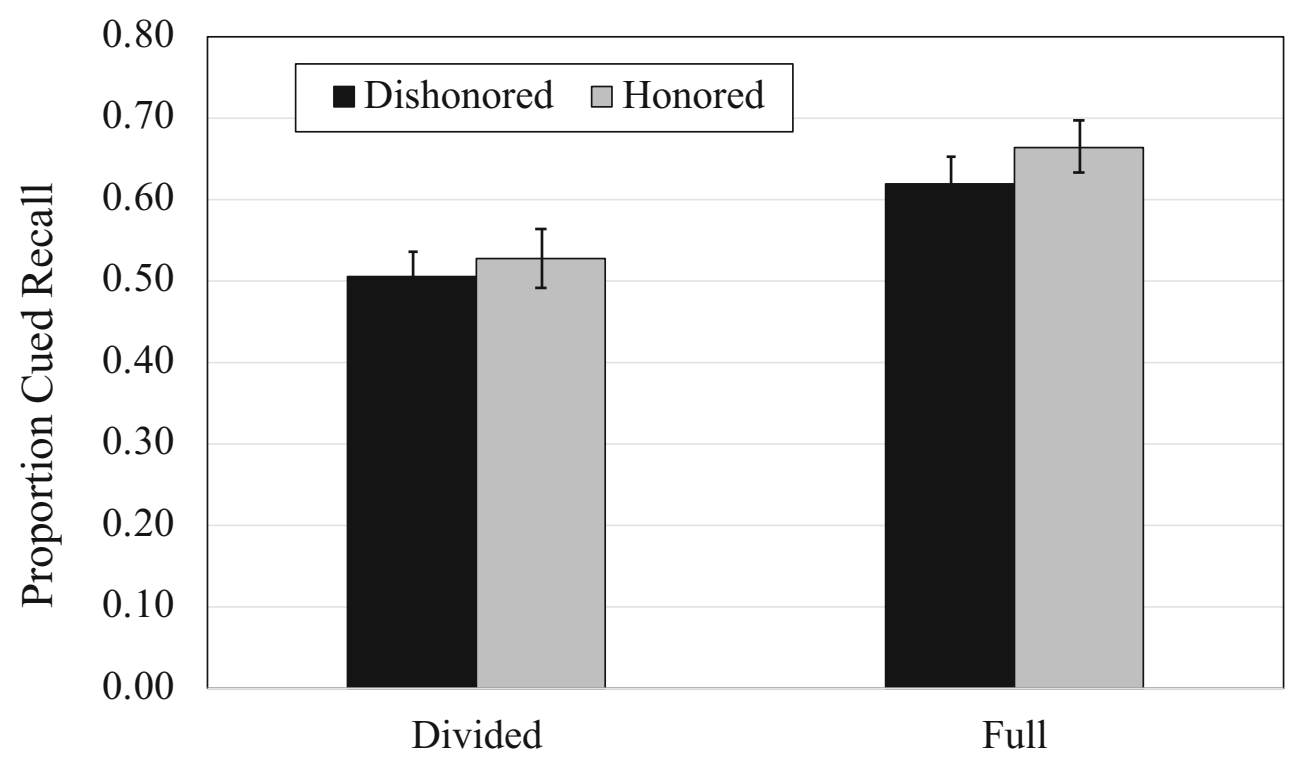

Fig. 5 Cued recall as a function of attention and honor conditions in Experiment 3. Error bars represent one standard error of the mean above and below the sample mean

Dividing attention in younger adults may yield selfregulation that is analogous to that among older adults, who typically have reduced attentional resources (Craik \& Byrd, 1982). Older adults consistently show preserved monitoring skills (Hertzog \& Dunlosky, 2011), but sometimes show impaired metacognitive control (Hertzog \& Hultsch, 2000; Tullis \& Benjamin, 2012). For example, in Tullis and Benjamin (2012), younger and older participants both selected to restudy the worst learned items, but these choices only benefited younger participants. These results mirror the current results: Both full and divided attention groups mostly selected to restudy the worst learned items, but only the full attention group benefited from their selections. Younger learners under divided attention and older adults show no impairments in their ability to monitor their learning, but both groups show impaired efficacy of control.

Across the three experiments, dividing attention yielded greater overestimation of learning than full attention (but this difference did not reach significance in Experiment 1). Accurate calibration may require attentional resources. For unfamiliar tasks, participants may anchor metacognitive predictions near the midpoint of a scale (Connor et al., 1997). They, then, adjust their JOLs according to their knowledge of specific conditions (e.g., divided attention). Adjusting JOLs away from an anchor requires attentional resources (Epley \& Gilovich, 2004). In other words, learners' general beliefs about learning conditions affect how they shift their predictions away from an anchor; utilizing those overarching beliefs to inform item-by-item JOLs may be an effortful process (Undorf et al., 2018). Further, the betweenparticipants design of the current experiments prevents comparisons between the different conditions within each participant. Future studies that allow learners to complete both conditions within a single list could improve comparisons between the conditions and prompt more accurate predictions (e.g., Susser et al., 2013).

Broadly, components of metacognition demand differing levels of cognitive resources. Learners can accurately identify poorly learned materials under divided attention when they can infer learning from diagnostic, mnemonic cues about processing fluency. However, under divided attention, learners struggle to use that accurate monitoring to direct their study choices and metacognitive control suffers. By examining resolution of JOLs and the efficacy of item-by-item control, this study demonstrates significant limitations of effective metacognitive control under divided attention. Students may struggle to effectively control learning in complex and realworld settings, where they consistently divide attention between multiple tasks. Understanding how to support learners' metacognition, even when attention is divided, is an important step to structuring environments to bolster student performance.

Supplementary Information The online version contains supplementary material available at https://doi.org/10.3758/s13423-021-01950-9.

Acknowledgments This research was supported in part by the Research and Project Grants from the Graduate and Professional Student Council of the University of Arizona.

Open practices statement The datasets generated during the current study are available in the Open Science Framework repository (https:// osf.io/y4ts7/?view_only $=$ fff4727d801c4f569431fe4c6684f57d). None of the experiments was preregistered. 


\section{References}

Ariel, R. (2013). Learning what to learn: The effects of task experience on strategy shifts in the allocation of study time. Journal of Experimental Psychology: Learning, Memory, and Cognition, 39(6), 1697-1711. https://doi.org/10.1037/a0033091

Ariel, R., Al-Harthy, I. S., Was, C. A., \& Dunlosky, J. (2011). Habitual reading biases in the allocation of study time. Psychonomic Bulletin \& Review, 18(5), 1015-1021. https://doi.org/10.3758/s13423-0110128-3

Ariel, R., \& Dunlosky, J. (2013). When do learners shift from habitual to agenda-based processes when selecting items for study? Memory \& Cognition, 41(3), 416-428. https://doi.org/10.3758/s13421-0120267-4

Ariel, R., Dunlosky, J., \& Bailey, H. (2009). Agenda-based regulation of study-time allocation: When agendas override item-based monitoring. Journal of Experimental Psychology: General, 138(3), 432447. https://doi.org/10.1037/a0015928

Barnes, K. A., \& Dougherty, M. R. (2007). The effect of divided attention on global judgment of learning accuracy. The American Journal of Psychology, 120(3), 347-359. https://doi.org/10.2307/20445409

Beaman, C. P., Hanczakowski, M., \& Jones, D. M. (2014). The effects of distraction on metacognition and metacognition on distraction: Evidence from recognition memory. Frontiers in Psychology, 5, Article 439. https://doi.org/10.3389/fpsyg.2014.00439

Benjamin, A. S., \& Bird, R. D. (2006). Metacognitive control of the spacing of study repetitions. Journal of Memory and Language, 55(1), 126-137. https://doi.org/10.1016/j.jml.2006.02.003

Boekaerts, M., \& Niemivirta, M. (2000). Self-regulated learning: Finding a balance between learning goals and ego-protective goals. In M. Boekaerts, P. R. Pintrich, \& M. Zeidner (Eds.), Handbook of selfregulation (pp. 417-450). Academic. https://doi.org/10.1016/B978012109890-2/50042-1

Burak, L. J. (2012). Multitasking in the university classroomInternational Journal for the Scholarship of Teaching and Learning, 6(2), Article 8. https://doi.org/10.20429/ijsotl.2012.060208

Carrier, L. M., Rosen, L. D., Cheever, N. A., \& Lim, A. F. (2015). Causes, effects, and practicalities of everyday multitasking. Developmental Review, 35, 64-78. https://doi.org/10.1016/j.dr. 2014.12.005

Connor, L. T., Dunlosky, J., \& Hertzog, C. (1997). Age-related differences in absolute but not relative metamemory accuracy. Psychology and Aging, 12(1), 50-71. https://doi.org/10.1037/ 0882-7974.12.1.50

Craik, F. I., \& Byrd, M. (1982). Aging and cognitive deficits. In F. I. M. Craik \& S. E. Trehub (Eds.), Aging and Cognitive Processes (pp. 191-211). Plenum. https://doi.org/10.1007/978-1-4684-4178-9_11

Craik, F. I., Naveh-Benjamin, M., Ishaik, G., \& Anderson, N. D. (2000). Divided attention during encoding and retrieval: Differential control effects? Journal of Experimental Psychology: Learning, Memory, and Cognition, 26(6), 1744-1749. https://doi.org/10.1037/02787393.26.6.1744

Dunlosky, J., \& Thiede, K. W. (2004). Causes and constraints of the shiftto-easier-materials effect in the control of study. Memory \& Cognition, 32(5), 779-788. https://doi.org/10.3758/BF03195868

Efklides, A. (2011). Interactions of metacognition with motivation and affect in self-regulated learning: The MASRL model. Educational Psychologist, 46(1), 6-25. https://doi.org/10.1080/00461520.2011. 538645

Ellis, Y., Daniels, B., \& Jauregui, A. (2010). The effect of multitasking on the grade performance of business students. Research in Higher Education Journal, 8, 1-10.

Epley, N., \& Gilovich, T. (2004). Are adjustments insufficient? Personality and Social Psychology Bulletin, 30(4), 447-460. https://doi.org/10.1177/0146167203261889
Finley, J. R., Benjamin, A. S., \& McCarley, J. S. (2014). Metacognition of multitasking: How well do we predict the costs of divided attention? Journal of Experimental Psychology: Applied, 20(2), 158165. https://doi.org/10.1037/xap0000010

Hanczakowski, M., Beaman, C. P., \& Jones, D. M. (2018). Learning through clamor: The allocation and perception of study time in noise. Journal of Experimental Psychology: General, 147(7), 1005-1022. https://doi.org/10.1037/xge0000449

Hertzog, C., \& Dunlosky, J. (2011). Metacognition in later adulthood: Spared monitoring can benefit older adults' self-regulation. Current Directions in Psychological Science, 20(3), 167-173. https://doi. org/10.1177/0963721411409026

Hertzog, C., Dunlosky, J., \& Sinclair, S. M. (2010). Episodic feeling-ofknowing resolution derives from the quality of original encoding. Memory \& Cognition, 38(6), 771-784. https://doi.org/10.3758/MC. 38.6.771

Hertzog, C., \& Hultsch, D. F. (2000). Metacognition in adulthood and old age. In F. I. M. Craik \& T. A. Salthouse (Eds.), The handbook of aging and cognition (pp. 417-466). Erlbaum.

Junco, R., \& Cotten, S. R. (2011). Perceived academic effects of instant messaging use. Computers \& Education, 56(2), 370-378. https:// doi.org/10.1016/j.compedu.2010.08.020

Junco, R., \& Cotten, S. R. (2012). No A 4 U: The relationship between multitasking and academic performance. Computers \& Education, 59(2), 505-514. https://doi.org/10.1016/j.compedu.2011.12.023

Kanfer, R., \& Ackerman, P. L. (1989). Motivation and cognitive abilities: An integrative/aptitude-treatment interaction approach to skill acquisition. Journal of Applied Psychology, 74(4), 657-690. https:// doi.org/10.1037/0021-9010.74.4.657

Koriat, A. (1997). Monitoring one's own knowledge during study: A cueutilization approach to judgments of learning. Journal of Experimental Psychology: General, 126(4), 349-370. https://doi. org/10.1037/0096-3445.126.4.349

Kornell, N., \& Metcalfe, J. (2006). Study efficacy and the region of proximal learning framework. Journal of Experimental Psychology: Learning, Memory, and Cognition, 32(3), 609-622. https://doi.org/10.1037/0278-7393.32.3.609

Mazzoni, G., \& Cornoldi, C. (1993). Strategies in study time allocation: Why is study time sometimes not effective? Journal of Experimental Psychology: General, 122(1), 47-60. https://doi.org/ 10.1037/0096-3445.122.1.47

Metcalfe, J., \& Finn, B. (2008). Evidence that judgments of learning are causally related to study choice. Psychonomic Bulletin \& Review, 15(1), 174-179. https://doi.org/10.3758/PBR.15.1.174

Miele, D. B., \& Molden, D. C. (2010). Naive theories of intelligence and the role of processing fluency in perceived comprehension. Journal of Experimental Psychology: General, 139(3), 535-557. https://doi. org/10.1037/a0019745

Mulligan, N. W. (1998). The role of attention during encoding in implicit and explicit memory. Journal of Experimental Psychology: Learning, Memory, and Cognition, 24(1), 27-47. https://doi.org/ 10.1037/0278-7393.24.1.27

Mulligan, N. W. (2008). Attention and Memory. In H. L. Roediger (Ed.), Learning and memory: A comprehensive reference (Vol. 2, pp. 7 22). Elsevier. https://doi.org/10.1016/b978-012370509-9.00134-0

Nelson, T. O. (1984). A comparison of current measures of the accuracy of feeling-of-knowing predictions. Psychological Bulletin, 95(1), 109-133. https://doi.org/10.1037/0033-2909.95.1.109

Nelson, T. O., \& Leonesio, R. J. (1988). Allocation of self-paced study time and the "labor-in-vain effect". Journal of Experimental Psychology: Learning, Memory, and Cognition, 14(4), 676-686. https://doi.org/10.1037/0278-7393.14.4.676

Nelson, D. L., McEvoy, C. L., \& Schreiber, T. A. (1998). The University of South Florida word association, rhyme, and word fragment norms. Retrieved August 15, 2017, from http://w3.usf.edu/ FreeAssociation/ 
Nelson, T. O., \& Narens, L. (1990). Metamemory: A theoretical framework and new findings. The Psychology of Learning and Motivation, 26, 125-141. https://doi.org/10.1016/s0079-7421(08) 60053-5

Patterson, M. C. (2017). A naturalistic investigation of media multitasking while studying and the effects on exam performance. Teaching of Psychology, 44(1), 51-57. https://doi.org/10.1177/ 0098628316677913

Peng, Y., \& Tullis, J. G. (2019). Theories of intelligence influence selfregulated study choices and learning. Journal of Experimental Psychology: Learning, Memory, and Cognition, 46(3), 487-496. https://doi.org/10.1037/xlm0000740

Sacher, M., Isingrini, M., \& Taconnat, L. (2013). Effects of aging and divided attention on episodic feeling-of-knowing accuracy. Acta Psychologica, 144(2), 258-263. https://doi.org/10.1016/j.actpsy. 2013.07.004

Sacher, M., Taconnat, L., Souchay, C., \& Isingrini, M. (2009). Divided attention at encoding: Effect on feeling-of-knowing. Consciousness and Cognition, 18(3), 754-761. https://doi.org/10.1016/j.concog. 2009.04.001

Son, L. K. (2004). Spacing one's study: evidence for a metacognitive control strategy. Journal of Experimental Psychology: Learning, Memory, and Cognition, 30(3), 601-604. https://doi.org/10.1037/ 0278-7393.30.3.601

Son, L. K., \& Sethi, R. (2006). Metacognitive control and optimal learning. Cognitive Science, 30(4), 759-774. https://doi.org/10.1207/ s15516709cog0000_74

Susser, J. A., Mulligan, N. W., \& Besken, M. (2013). The effects of list composition and perceptual fluency on judgments of learning (JOLs). Memory \& Cognition, 41(7), 1000-1011. https://doi.org/ 10.3758/s13421-013-0323-8

Thiede, K. W. (1999). The importance of monitoring and self-regulation during multitrial learning. Psychonomic Bulletin \& Review, 6(4), 662-667. https://doi.org/10.3758/bf03212976

Thiede, K. W., Anderson, M., \& Therriault, D. (2003). Accuracy of metacognitive monitoring affects learning of texts. Journal of
Educational Psychology, 95(1), 66-73. https://doi.org/10.1037/ 0022-0663.95.1.66

Thiede, K. W., \& Dunlosky, J. (1999). Toward a general model of selfregulated study: An analysis of selection of items for study and selfpaced study time. Journal of Experimental Psychology: Learning, Memory, and Cognition, 25(4), 1024-1037. https://doi.org/10.1037/ 0278-7393.25.4.1024

Tullis, J. G., \& Benjamin, A. S. (2011). On the effectiveness of self-paced learning. Journal of Memory and Language, 64(2), 109-118. https://doi.org/10.1016/j.jml.2010.11.002

Tullis, J. G., \& Benjamin, A. S. (2012). Consequences of restudy choices in younger and older learners. Psychonomic Bulletin \& Review, 19(4), 743-749. https://doi.org/10.3758/s13423-012-0266-2

Tullis, J. G., Fiechter, J. L., \& Benjamin, A. S. (2018). The efficacy of learners' testing choices. Journal of Experimental Psychology: Learning, Memory, and Cognition, 44(4), 540-552. https://doi.org/ $10.1037 / x \operatorname{lm} 0000473$

Tullis, J. G., \& Fraundorf, S. H. (2017). Predicting others' memory performance: The accuracy and bases of social metacognition. Journal of Memory and Language, 95, 124-137. https://doi.org/10.1016/j. jm1.2017.03.003

Undorf, M., \& Erdfelder, E. (2015). The relatedness effect on judgments of learning: A closer look at the contribution of processing fluency. Memory \& Cognition, 43(4), 647-658. https://doi.org/10.3758/ s13421-014-0479-x

Undorf, M., Söllner, A., \& Bröder, A. (2018). Simultaneous utilization of multiple cues in judgments of learning. Memory \& Cognition, 46(4), 507-519. https://doi.org/10.3758/s13421-017-0780-6

Winne, P. H., \& Hadwin, A. F. (1998). Studying as self-regulated learning. In D. J. Hacker, J. Dunlosky, \& A. Graesser (Eds.), Metacognition in educational theory and practice (pp. 277-304). Erlbaum.

Publisher's note Springer Nature remains neutral with regard to jurisdictional claims in published maps and institutional affiliations. 